\title{
DIAGNOSTIC AND THERAPEUTIC CHALLENGE IN A CHILD WITH OSTEOGENESIS IMPERFECTA-CASE REPORT AND LITERATURE REVIEW
}

\author{
Maria Daniela Trăilescu ${ }^{1,2}$, Adrian Ionel Pavel ${ }^{1,2}$, Alexandru Mircea Pop ${ }^{1}$
}

\begin{abstract}
The treatment of fractures in children with osteogenesis imperfecta depends on several factors: the patient's age, the type and location of the fracture, the degree of fracture displacement and the type of osteogenesis imperfecta. Operative management varies and evidence is limited. We present a case report of operative treatment in an 8-year-old boy, admitted to our hospital within two years with displaced femoral shaft fractures. The past medical history was significant for multiple fractures managed conservatively. During the first hospitalization, after osteosynthesis of the right femoral shaft fracture, we extended the investigations for bone fragility. The history, clinical signs, low bone mineral density (BMD) level and genetic test, all led to the diagnosis of osteogenesis imperfecta type IV. After 1 year and 3 months from the first osteosynthesis with titanium elastic nails the patient returns to our emergency department with left displaced femoral shaft fracture. This time we stabilized the shaft fracture with the same type of osteosynthesis with elastic titanium nails. At two years after surgery, we found no inequalities of the lower limbs or joint stiffness.
\end{abstract}

Keywords: minimally invasive osteosynthesis, titanium elastic nails, genetic test, osteogenesis imperfecta

\section{Introduction}

Osteogenesis imperfecta (OI) is a group of genetic disorders characterized by bone fragility. The most wellknown consequence of $\mathrm{OI}$ is the occurrence of multiple and recurrent fractures without major trauma. Since 1979, the classification by Sillence is the most widely used and it is based on modes of inheritance, radiological and clinical findings and includes OI types I (mild non-deforming), II (perinatal lethal), III (severe), IV (moderate to severe) [1]. It has been known for three decades that the majority of individuals with $\mathrm{OI}$ have mutations in COL1A1 or COL1A2, the two genes coding for collagen type I alpha chains, but in the past 10 years defects in at least 17 other genes have been linked to OI [2]. There's no cure for OI and the management is multidisciplinary. The goals of therapy are to reduce fracture rate, prevent long bone deformities, minimize chronic pain, and maximize functional capacity [3]. Orthopedic treatment is part of the multidisciplinary approach providing correction of long bone bowing, rotational malalignment, angular deformity and preventing fractures [4-6]. Fractures in OI are treated with orthopedic procedures appropriate for the type of fracture and the age, the evolution towards healing of the fractures being also dependent on the medical treatment of the bone fragility. The aim of this paper is to present our experience in a child late diagnosed with osteogenesis imperfecta.

\section{Material and method}

We present the case of a boy of 8 years 3 months old (height $91 \mathrm{~cm}$, weight $20.1 \mathrm{~kg}$ ) presented in our emergency room with acute pain and functional failure of the right leg, after falling from roughly the same height. Prior to the clinical examination, the patient's mother informed us that in the last three years the boy had multiple non-displaced fractures involving the right clavicle, bilateral radius buckle fractures, radial head and which fractures had been treated conservatively. Even in the last year, before this presentation in our hospital, at the age of 7 years, he was treated conservatively with casts immobilization for similar proximal tibial fractures, produced by falling from the same height, fractures occurring at 6-month intervals. The only radiographs with the previous child's fractures, owned by the patient's mother and presented to us, confirmed fractures of the proximal metaphysis of the bilateral tibia and plastic deformations of the tibia underlying the fractures (Figure 1).

Examination of the right lower limb revealed its shortening by 3 centimeters, obvious deformation at the level of the right thigh with external rotation of the lower extremity. At the clinical examination we did not find any deformities in the segments affected by the previous fractures. On palpation we found the interruption of the bony continuity of the right femur and bone crackling.

His radiographs revealed displaced right femoral shaft fracture and moderate osteopenia (Figure 2a). The complete blood count of the child was unremarkable. All usual parameters: white blood cell count, red blood cell count, platelet count, hemoglobin and hematocrit, were in normal limits. Two titanium elastic nails (TEN) of $3 \mathrm{~mm}$ diameters were inserted retrograde through two distal short incisions, proximal to the distal right femoral growth plate (Figure 2 b). The postoperative evolution was favorable with analgesic medication and cast immobilization maintained for 30 days.

${ }^{1}$ Department of Pediatric Surgery and Orthopedics, Emergency County Hospital, Arad, Romania

${ }^{2}$ Faculty of Medicine, "Vasile Goldiş" Western University of Arad, Romania

E-mail: trailescumaria@yahoo.com, adipavel72@yahoo.com, alexanpop@yahoo.com 


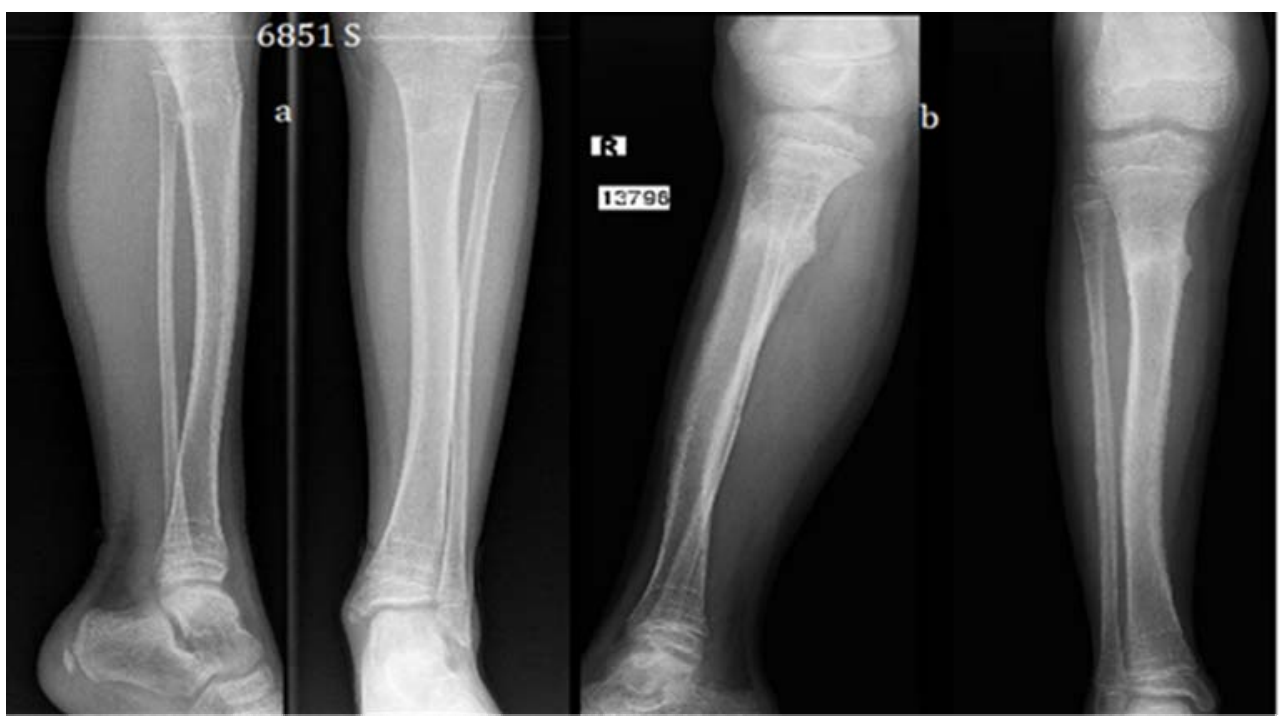

Fig.1. Fractures of the proximal metaphysis of the bilateral tibia (left tibia - a, and right tibia - b) and plastic deformations of the tibia underlying the fractures.

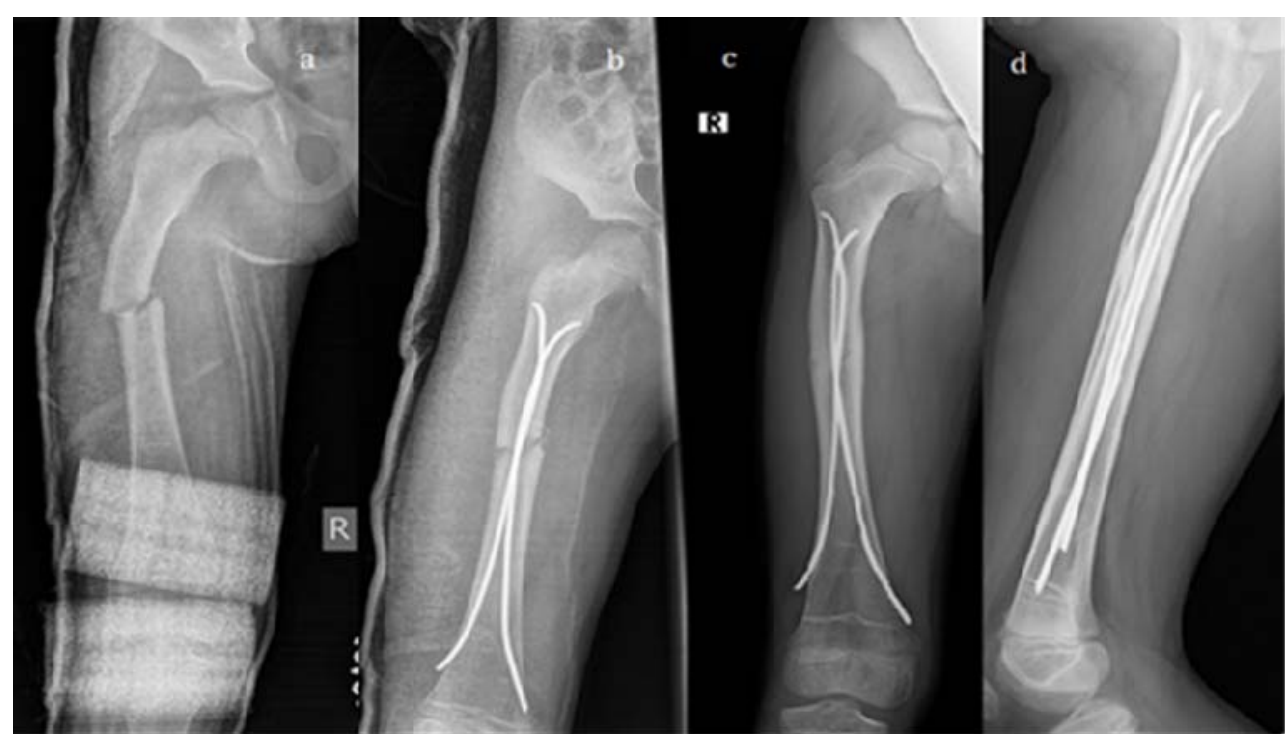

Fig.2. Radiological aspect of right femoral shaft fracture preoperatively (a), immediately after osteosynthesis with TEN (b) and postoperatively at 9 months (c, d).

Based on the medical history, clinical and radiographic data, a provisional diagnosis of an osteogenesis imperfecta was made.

Due to the stature-weight retardation (waist age of 5 years and 7 months) and the multiple fractures existing in the patient's past, we extended the investigations. Serum creatinine, magnesium, PTH, TSH, and free thyroxine were normal. Serum vitamin D levels and gonadotropin levels identified severe hypovitaminosis $\mathrm{D}(21 \mathrm{nmol} / \mathrm{L})$ and growth deficit due to low growth hormone level $(0.05 \mathrm{ng} / \mathrm{mL})$. The bone osteodensitometry of the lumbar spine (L1-L4) made with GE Lunar DPX (GE Healthcare) at dose $5 \mu \mathrm{Sv}$ allowed the calculation of the T score (bone density relative to that of a healthy patient of the same age and sex) and the diagnosis of imperfect osteogenesis, the $\mathrm{T}$ score being of -3.02 (low bone density) in the presence of several fractures in the antecedents.Considering the importance of the genetic test to confirm the diagnosis of imperfect osteogenesis type, it was recommended for the patient. The sequencing was performed in collaboration with the Center for Genomic Medicine Timisoara, research laboratory, using the Illumina TruSight One Sequencing Panel kit, a large panel that includes 4813 genes. 


\begin{tabular}{|l|l|l|l|l|l|}
\hline $\begin{array}{l}\text { Mean Region } \\
\text { Coverage Depth }\end{array}$ & $\begin{array}{l}\text { Uniformity of Coverage } \\
(\text { Pct }>0.2 * \text { mean) }\end{array}$ & $\begin{array}{l}\text { Target } \\
\text { Coverage } \\
\text { at 1X }\end{array}$ & $\begin{array}{l}\text { Target } \\
\text { Coverage } \\
\text { at 10X }\end{array}$ & $\begin{array}{l}\text { Target } \\
\text { Coverage } \\
\text { at 20X }\end{array}$ & $\begin{array}{l}\text { Target } \\
\text { Coverage } \\
\text { at 50X }\end{array}$ \\
\hline $110.8 \mathrm{X}$ & $97.5 \%$ & $99.9 \%$ & $99.2 \%$ & $98.0 \%$ & $90.6 \%$ \\
\hline
\end{tabular}

Fig. 3. Enrichment sequencing report - Coverage level for target nucleotides in the patient sample

The next generation sequencing technique was used using the MiSeq Illumina platform, which allows the analysis of coding sequences in genomic DNA. In the first stage, the fragmentation of the genomic DNA was performed, followed by the amplification of the coding sequences and the generation of libraries using the Illumina TruSight One Sequencing Panel kit. The coverage level for the target nucleotides in the analyzed sequences is shown in Figure 3.

End-to-end bioinformatics algorithms have been implemented, including nitrogen base alignment, primary filtration of lowquality readings and probable artifacts and annotation of variants, using Isis (Analysis Software) 2.5.2.3; BWA (Aligner) 0.7.9a-isis-1.0.1; SAMtools 0.1.18 (r982: 295); GATK (v1.6-23-gf0210b3) 1.7. The data analysis was performed at the level of current knowledge, using the UCSC Genome Browser, OMIM (Online Mendelian Inheritance in Man), DGV (Database of Genomic Variants) databases. All variants that may cause diseases reported in $\mathrm{HGMD} \AA$, ClinVar (class 1), as well as all variants with a minor allele frequency (MAF) of less than $1 \%$ in the ExAc database were considered.

The patient began treatment with subcutaneous injections with Somatotropin $0,025 \mathrm{mg} / \mathrm{kg} / \mathrm{day}$, a regular intake of calcium $(1000 \mathrm{mg} /$ day $)$, and an adequate intake of vitamin D (1000 IU/day).

Due to low bone density, we allowed the progressive loading of the right lower limb after one month from osteosynthesis.

At 9 months postoperative, radiological healing of the fracture stabilized by osteosynthesis with titanium elastic nails was confirmed, healing without hypertrophic osseous callus (Figure 2c, 2d). We observed a decrease in the degree of osteoporosis and a general mineralization of the femur with the thickening of the femoral cortex. The titanium elastic nails removal was performed 1 year postoperatively and we recommended limiting physical activity due to the bone fragility characteristic of the disease.

After 1 year and 3 months from the first osteosynthesis surgery (3 months after the removal of titanium elastic nails from the right femur) the patient returns to our emergency department with left displaced femoral shaft fracture, produced by falling from bed (Figure $4 \mathrm{a}, 4 \mathrm{~b}$ ). Two titanium flexible nails of $3,5 \mathrm{~mm}$ diameters were inserted retrograde through two distal short incisions, proximal to the distal left femoral growth plate (Figure 4c).

The postoperative evolution was favorable with radiological healing of the fracture at 9 months postoperative (Figure 4d). The titanium elastic nails removal was performed 1 year postoperatively

The patient continued treatment with subcutaneous injections with Somatotropin $0,025 \mathrm{mg} / \mathrm{kg} /$ day, a regular intake of calcium $(500 \mathrm{mg} /$ day $)$, and an adequate intake of vitamin D (1000 IU/day).

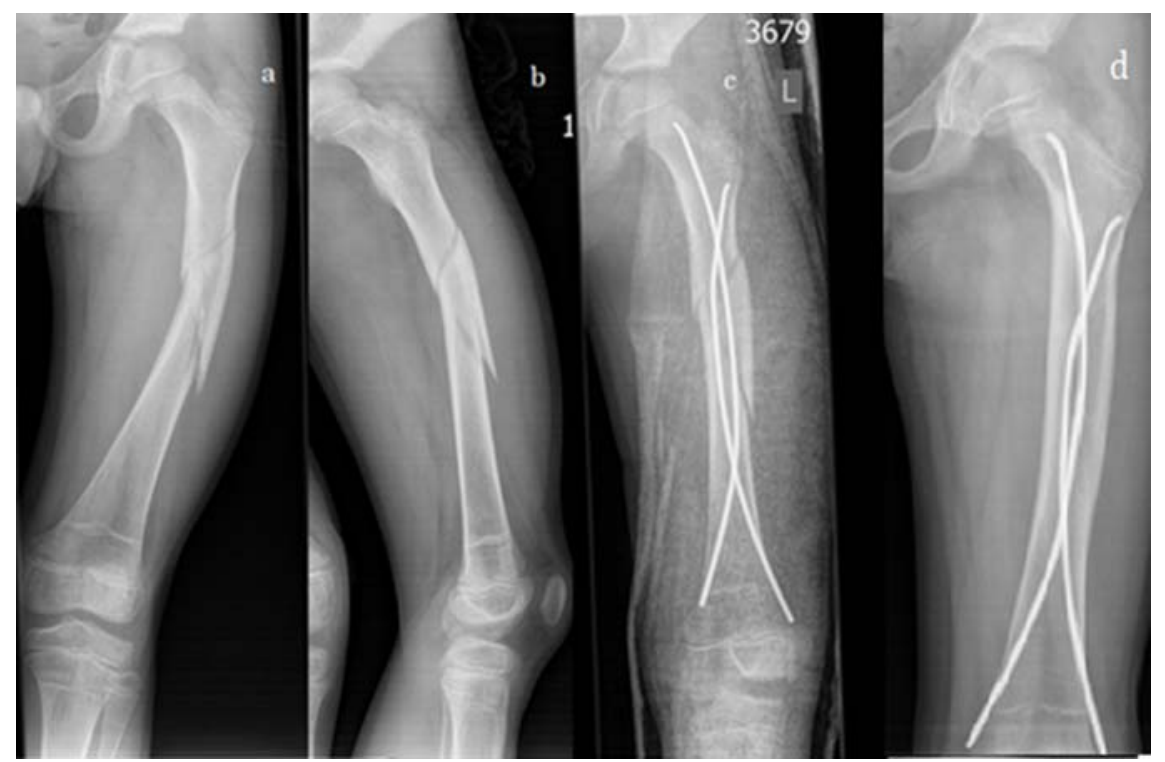

Fig.4. Radiological aspect of left femoral shaft fracture preoperatively (a and b), immediately after osteosynthesis with TEN (c) and postoperatively at 9 months (d). 


\section{Discussion}

Originally named "osteomalacia congenita," osteogenesis imperfecta was first medically described by Ekman in 1778 and classified 200 years later by Sillence [1].

The term OI encompasses a broad range of clinical presentations that may be first apparent from early in pregnancies to late in life, reflecting the extent of bone deformity and fracture predisposition at different stages of development or postnatal ages [7]. Depending on the age of presentation, OI can be difficult to distinguish from some other genetic and nongenetic causes of fractures, including nonaccidental injury [8]. In childhood, in the absence of a positive family history, most children newly diagnosed with OI are identified after one or more fractures. The differential diagnosis for frequent fracture in childhood is relatively limited and includes both inherited and acquired conditions. Hypophosphatasia, osteopetrosis with renal tubular acidosis, hypophosphatemic osteomalacia and nonaccidental injury should be considered [9-11].

Undisplaced fractures are treated by standard orthopedic measures appropriate for the age of the patient and the type of fracture.

The purpose of the surgical treatment of fractures is the elimination and prevention of fragments displacement, pain reduction, and immobilization terms reduction with the possibility of early activation. The basic principle of surgical treatment is restoring limb anatomy and intramedullary splinting at the maximum extent of the bone. The use of multiple long bone osteotomies secured with intramedullary rod fixation is the treatment principle described by Sofield in the 1950's and this continues to be used in the present [12-15].

The literature describes using the following structures for fixing bone fragments: non-telescopic (Rush nail, Kuntscher's pin), titanium elastic nails (TEN), Kirchner pins, telescopic internal fixation devices (Bailey-Dubow, Sheffield, Fassier-Duval rods), plates, and external fixation devices $[16,17]$.

In children, telescopic rods such as the Fassier-Duval and the Sheffield telescopic intramedullary rod system have become known and accepted, although reoperation and complication rates are high $[18,19]$.

The current methods of orthopedic surgical treatment described and reported in the literature in fractures children with osteogenesis imperfecta refer especially to osteogenesis imperfecta type I [13, 15-17].

The use of TEN may be considered as a less invasive approach compared to telescopic nail surgery, however only temporarily, as it will still most probably require a surgical revision a few years down the line, in moderate or severe osteogenesis imperfecta types [20].

Other authors consider that flexible intramedullary nails have specific contraindication in growing OI children although they can be used in young OI adults with good cortical bone [21].

Like other authors, we consider the selection of surgical techniques is dependent on surgeon experience, type of OI and patient function, and availability of specific instrumentation [22].

Because our department does not have telescopic rods, the only intramedullary rods we can use in children are the titanium elastic nails and that is why we used them in the osteosynthesis of the case presented. We chose this type of osteosynthesis for the minimally invasive nature of the surgical technique and for the stability of site fracture produced by the intramedullary insertion of the curved titanium nails. Although opinions are divided, by the favorable evolution of the case presented, we demonstrated that the minimally invasive osteosynthesis with titanium elastic nails is the optimal method of surgical treatment for femoral shaft fractures in children with osteogenesis imperfecta type IV.

We have shown that flexible intramedullary rods have no specific contraindications in raising OI type IV children.

In childhood, the clinical examination is the key first step in evaluation of the child with suspected OI. The evaluation requires familiarity with the natural history and variation in clinical presentation of OI, particularly in the infant or toddler [23]. Mild forms of OI may go unnoticed by even experienced general clinicians. Referral to an experienced physician familiar with the range of clinical expression of $\mathrm{OI}$ is relatively inexpensive in comparison to laboratory testing and may be all that is necessary to secure the diagnosis $[7,24,25]$.

The peculiarity of this case consists in the late diagnosis of imperfect osteogenesis in a child who until the presentation in our service had a suggestive history for this disease and suggestive radiological signs such as tibial fractures accompanied by plastic deformities. Based on the medical history, clinical and radiographic data, a provisional diagnosis of an osteogenesis imperfecta was made but was difficult to differentiated a form a mild form of OI or OI type IV (with white sclerae) from nonaccidental injury, juvenile idiopathic osteoporosis or the some other genetic and nongenetic causes of fractures $[7,26$ $-29]$.

Therefore, we recommended additional investigations that confirmed the type of osteogenesis imperfecta, very important for the treatment, monitoring and prognosis of the patient.

By sequencing analysis using a large panel of 4813 genes (Illumina TruSight One Sequencing Panel), a variant, in heterozygous status, was detected in the COL1A2 gene located on chromosome 7q21.3. The missense variant c. $1009 \mathrm{G}>\mathrm{A}$, shows coverage on the spot $150 \mathrm{X}$ variant. This sequence change replaces glycine with serine at codon 337 of COL1A2 protein (p.Gly337Ser). The glycine residue is highly conserved and there is a small physicochemical difference between glycine and serine. This variant is not present in the bases of population data (ExAC, GnomAD without frequency). This variant has been reported in several individuals affected by imperfect osteogenesis types I, III and IV [30-35].

Pathogenic variants in heterozygous status in the COL1A2 gene have been associated with several phenotypes, of which osteogenesis imperfecta type IV (OMIM 166220) is the most relevant for the patient [36]. 
In our country, especially in rural areas, parents find it difficult to accept the existence of a rare disease and special treatment for these patients, hoping that these fractures occur only due to carelessness or physical activity characteristic of age.

In the present case, the patient's parents were compliant, cooperative and understood the importance of continuing the treatment instituted in hospital for the correction of hypovitaminosis $\mathrm{D}$, for the recovery of growth retardation and calcium deficiency.

\section{Conclusions}

Diagnosing and treating a child with imperfect osteogenesis requires further investigation and a multidisciplinary team approach for a good therapeutic outcome. The treatment of fractures that occur on the basis of bone fragility, characteristic of imperfect osteogenesis, is not standardized and continues to be a challenge for the orthopedic physician. In case of patients with multiple fractures in the medical history, young orthopedic surgeons on duty and emergency department physicians should take these symptoms seriously and be highly suspicious of OI. Osteosynthesis with titanium elastic nails in children with osteogenesis imperfecta type IV and femoral shaft fractures can be a good solution in association with a suitable treatment of bone fragility. Genetic counseling plays an important role in this case because the risk of developing the disease in another pregnancy or other children of the patient's parents is theoretically $1 \%$, due to a possible gonadal mosaicism but the risk of developing the disease in the patient's descendants is $50 \%$, regardless of gender.

Conflicts of Interest: The authors declare no conflict of interest

\section{References}

1. Sillence DO, Senn A, Danks D. Genetic heterogeneity in osteogenesis imperfecta. J Med Genet.1979; 16,101116.

2. Trejo P, Rauch F. Osteogenesis imperfecta in children and adolescents - new developments in diagnosis and treatment. Osteoporos Int. 2016; 27, 3427-3437. https://doi.org/10.1007/s00198-016-3723-3.

3. Engelbert RH, Beemer FA, van der Graaf Y, Helders P.J Osteogenesis imperfecta in childhood: Impairment and disability - A follow up study. Arch Phys Med Rehabil. 1999; 80, 896-903.

4. Georgescu I, Vlad C, Gavriliu TS, Dan S, Parvan AA. Surgical treatment in osteogenesis imperfecta-10 years experience. J Med Life. 2013; 6, 205-213.

5. Barbu CM, Ulici A. Early telescopic rod osteosynthesis for osteogenesis imperfecta patients. J Med Life. 2015; 8, 544-547.

6. Roberts TT, Cepela DJ, Uhl RL, Lozman J. Orthopaedic considerations for the adult with osteogenesis imperfecta. J Am Acad Orthop Surg. 2016; 24, 298-308.

7. Byers P, Krakow D, Nunes M, et al. Genetic evaluation of suspected osteogenesis imperfecta (OI). Genet Med. 2006; vol. 8, 383-388.

8. Rauch F, Glorieux FH. Osteogenesis imperfecta. Lancet. 2004; 363:1377-1385.

9. Parfitt AM. Vitamin D and the pathogenesis of rickets and osteomalacia. In: Feldman D, Glorieux FH, Pike W, eds. Vitamin D. San Diego: Academic Press; 1997, 645-62.

10. Misra M, Pacaud D, Petryk A, Collett-Solberg PF, Kappy M. Vitamin D deficiency in children and its management: review of current knowledge and recommendations. Pediatrics. 2008; 122:398-417.
11. Lips P. Vitamin D deficiency and secondary hyperparathyroidism in the elderly: consequences for bone loss and fractures and therapeutic implications. Endocr Rev. 2001; 22:477-501.

12. Biggin A, Munns CF. Osteogenesis imperfecta: diagnosis and treatment. Curr Osteoporos Rep. 2014; 12:279-288.

13. Saraff V, Hogler W. Osteoporosis in children: diagnosis and management. Eur J Endocrinol. 2015; 173: R185R197.

14. Harrington J, Sochett E, Howard A. Update on the evaluation and treatment of osteogenesis imperfecta. Pediatr Clin North Am. 2014; 61:1243-1257.

15. Sofield HA, Millar EA. Fragmentation, realignment, and intramedullary rod fixation of deformities of the long bones in children: a ten years appraisal. J Bone Joint Surg Am. 1979; 41-A:1371-91.

16. Burtsev ME., Frolov A., Logvinov AN, et al. Current approach to diagnosis and treatment of children with osteogenesis imperfecta. Pediatric Traumatology, Orthopaedics and Reconstructive Surgery. 2019; Vol. 7. - N. 2. - P. 87-102. doi: 10.17816/PTORS7287-102.

17. Nicolaou N, Bowe JD, Wilkinson JM, Fernandes JA, Bell MJ. Use of the Sheffield telescopic intramedullary rod system for the management of osteogenesis imperfecta: clinical outcomes at an average follow-up of nineteen years. J Bone Joint Surg Am. 2011; 93:1994-2000. doi: 10.2106/JBJS.J.01893

18. Birke O, Davies N, Latimer M, Little DG, Bellemore M. Experience with the Fassier-Duval telescopic rod: first 24 consecutive cases with a minimum of 1-year follow-up. J Pediatr Orthop. 2011; 31:458-64. doi: 10.1097/BPO.0b013e31821bfb50. 
19. Agarwal V, Joseph B. Non-union in osteogenesis imperfecta. J Pediatr Orthop B. 2005; 14:451-5. doi: 10.1097/01202412-200511000-00013.

20. Persiani P, Martini L, Ranaldi FM, Zambrano A, Celli M, Celli L, D'Eufemia P, Villani C. Elastic intramedullary nailing of the femur fracture in patients affected by osteogenesis imperfecta type 3: Indications, limits and pitfalls. Injury. 2019 Jul;50 Suppl 2: S52S56. doi: 10.1016/j.injury.2019.01.045.

21. Monti E, Mottes M, Fraschini P, et al. Current and emerging treatments for the management of osteogenesis imperfecta. Ther Clin Risk Manag. 2010; no.6, pp. 367-81.

22. Esposito P, Plotkin H. Surgical treatment of osteogenesis imperfecta: current concepts. Current Opinion in Pediatrics. 2008; no. 20, 52-57.

23. Albright JA. Systemic treatment of osteogenesis imperfecta-Historic review. Abstract of symposium II on osteogenesis imperfecta. Curr Orthop Pract. 1976; 116:258.

24. Sule G, Campeau PM, Zhang VW et al. Nextgeneration sequencing for disorders of low and high bone mineral density. Osteoporos Int. 2013; 24:22532259.

25. Rauch F, Land C, Cornibert S, Schoenau E, Glorieux FH. High and low density in the same bone: a study on children and adolescents with mild osteogenesis imperfecta. Bone. 2005; 37:634-641.

26. Marini JC. Osteogenesis imperfecta. In: Nelson WE, Behrman RE, Kliegman RM, Arvin AM, editors. Nelson Textbook of Pediatrics. 18th ed. Philadelphia: W.B. Saunders Company. 2007; p. 2887-90.

27. Polousky JD, Eilert RE. Orthopedics. In: Hay WW, Levin MJ, Sondheimer JM, Deterding RR, editors. Current Pediatrics: Diagnosis and Treatment. Vol. 753, 19th ed. New York: McGraw Hill; 2009; 1005-1006.

28. Harrington J, Sochett E, Howard A. Update on the evaluation and treatment of osteogenesis imperfecta. Pediatr Clin North Am. 2014; 61:1243-1257.
29. Hoyer-Kuhn H, Netzer C, Semler O. Osteogenesis imperfecta: pathophysiology and treatment. Wien Med Wochenschr. 2015; 165:278-284.

30. Swinnen FK, Coucke PJ, De Paepe AM., et al. Osteogenesis Imperfecta: the audiological phenotype lacks correlation with the genotype. Orphanet journal of rare diseases. 2011; vol. 6, 88 .

31. Ho Duy B, Zhytnik L, Maasalu K, et al. Mutation analysis of the COL1A1 and COL1A2 genes in Vietnamese patients with osteogenesis imperfecta. Human genomics. 2016; no.10, 27.

32. Udomchaiprasertkul W, Kuptanon C, Porntaveetus T, Shotelersuk V. A family with homozygous and heterozygous p.Gly337 Ser mutations in COL1A2. Eur J Med Genet. 2020; 63(6):103896, doi: 10.1016/j.ejmg.2020.103896.

33. McInerney-Leo AM, Marshall MS, Gardiner B, Coucke PJ, Van Laer L, et al. Whole exome sequencing is an efficient, sensitive and specific method of mutation detection in osteogenesis imperfecta and Marfan syndrome. BoneKEy reports. 2013; no. 2, 456.

34. Zhang $\mathrm{H}$, Yue $\mathrm{H}$, Wang $\mathrm{C}$, $\mathrm{Hu} \mathrm{W}$ et al. Clinical characteristics and the identification of novel mutations of COL1A1 and COL1A2 in 61 Chinese patients with osteogenesis imperfecta. Molecular medicine reports. 2016; vol.14, 4918-4926.

35. Lindahl K, Astrom E, Rubin CJ, Grigelioniene G, Malmgren B, Ljunggren O, Kindmark A. Genetic epidemiology, prevalence, and genotype-phenotype correlations in the Swedish population with osteogenesis imperfecta. Eur J Hum Genet. 2015; 23:1042-1050.

36. Valadares ER, Carneiro TB, Santos PM, Oliveira AC, Zabel B. What is new in genetics and osteogenesis imperfecta classification? J Pediatr (Rio J). 2014; 90:536-541.

Correspondence to:

Maria Daniela Trăilescu

Department of Pediatric Surgery and Orthopedics,

Emergency County Hospital, Arad, Romania

Andreny Karolly Street, No.2 - 4,

Arad, 310037, România

Phone: +40-257- 220000

Email: trailescumaria@yahoo.com 